\title{
Transferability of vegetation recovery models based on remote sensing across different fire regimes
}

\author{
José Manuel Fernández-Guisuraga ${ }^{1}$ | Susana Suárez-Seoane ${ }^{2}$ (i) | Leonor Calvo ${ }^{1}$
}

${ }^{1}$ Area of Ecology, Faculty of Biological and Environmental Sciences, University of León, León, Spain

${ }^{2}$ Department of Organisms and Systems Biology (BOS; Ecology Unit) and Research Unit of Biodiversity (UO-CSIC-PA), University of Oviedo, Oviedo, Spain

\section{Correspondence}

José Manuel Fernández-Guisuraga, Area of Ecology, Faculty of Biological and Environmental Sciences, University of León, 24071 León, Spain.

Email: jofeg@unileon.es

Funding information

Ministerio de Educación, Cultura y Deporte, Grant/Award Number: FPU16/03070; Ministerio de Economía y Competitividad, Grant/Award Number: FIRESEVES (AGL2017-86075-C2-1-R) and GESFIRE (AGL2013-48189-C2-1-R); Consejería de Educación, Junta de Castilla y León, Grant/ Award Number: FIRECYL (LE033U14) and SEFIRECYL (LE001P17); Ministry of Economy and Competitiveness, Grant/ Award Number: LE033U14 and LE001P17; European Regional Development Fund; Ministry of Education, Grant/Award Number: FPU16 and 03070 Co-ordinating Editor: Hannes Feilhauer

\section{Abstract}

Aim: To evaluate the transferability between fire recurrence scenarios of post-fire vegetation cover models calibrated with satellite imagery data at different spatial resolutions within two Mediterranean pine forest sites affected by large wildfires in 2012.

Location: The northwest and east of the Iberian Peninsula.

Methods: In each study site, we defined three fire recurrence scenarios for a reference period of 35 years. We used image texture derived from the surface reflectance channels of WorldView-2 and Sentinel-2 (at a spatial resolution of $2 \mathrm{~m} \times 2 \mathrm{~m}$ and $20 \mathrm{~m} \times 20 \mathrm{~m}$, respectively) as predictors of post-fire vegetation cover in Random Forest regression analysies. Percentage vegetation cover was sampled in two sets of field plots with a size roughly equivalent to the spatial resolution of the imagery. The plots were distributed following a stratified design according to fire recurrence scenarios. Model transferability was assessed within each study site by applying the vegetation cover model developed for a given fire recurrence scenario to predict vegetation cover in other scenarios, iteratively.

Results: For both wildfires, the highest model transferability between fire recurrence scenarios was achieved for those holding the most similar vegetation community composition regarding the balance of species abundance according to their plant-regenerative traits (root mean square error [RMSE] around or lower than 15\%). Model transferability performance was highly improved by fine-grained remotesensing data.

Conclusions: Fire recurrence is a major driver of community structure and composition so the framework proposed in this study would allow land managers to reduce efforts in the context of post-fire decision-making to assess vegetation recovery within large burned landscapes with fire regime variability.

\section{KEYWORDS}

image texture, megafire, model transferability, random forest regression, satellite imagery, Sentinel-2, vegetation cover, WorldView-2 


\section{1 | INTRODUCTION}

Wildfires are one of the main disturbances in forest ecosystems around the world (Collins et al., 2018), having a significant effect on their biological productivity and composition (Calvo et al., 2008), as well as on their dynamics (Lozano et al., 2008). Particularly in the Mediterranean Basin, large forest fires are becoming more recurrent,

5 mainly due to global climate change (Quintano et al., 2015), which implies more adverse ecological effects (Pausas et al., 2008). These large and more recurrent fires may lead to severe post-fire environmental conditions (e.g., increased incident solar radiation), partial or total removal of vegetation cover and shifts in plant community structure and composition (Pausas et al., 2008; Taboada et al., 2017), due to induced variation in plant species fitness (Keeley et al., 2011).

In this sense, plant-regenerative traits are key in plant species fitness and, therefore, in community resilience against disturbances (Lloret et al., 2005; Keeley et al., 2011). In the western Mediterranean Basin, post-fire vegetation recovery relies on two plant-regenerative traits: (a) resprouting from above-ground or below-ground surviving tissues (Pausas \& Keeley, 2014; Moreira et al., 2012); and (b) seedling recruitment from canopy or soil banks (Pausas \& Keeley, 2014). Additionally, some species present both types of regeneration mechanisms and are referred to as facultative seeders (Pausas \& Keeley, 2014; Lloret et al., 2005). In general, the species assemblage of a single community presents both regeneration mechanisms (Pausas, 2001; Calvo et al., 2008), although the proportion of obligate resprouters, obligate seeders and facultative seeders is affected by fire regime (Lloret et al., 2005). For instance, it has been proposed that, under recurrent wildfires, obligate seeders could be hindered before they have accumulated a canopy or soil bank viable for persistence, obligate resprouter species being promoted (Pausas, 2001; Pausas \& Keeley, 2014; Lloret et al., 2005; Knox \& Morrison, 2005; Taboada et al., 2017; Taboada et al., 2018).

Due to the influence of fire recurrence on the balance between resprouter and seeder abundance and, therefore, on the community structure and composition, it should be possible to achieve vegetation recovery models transferable between different fire recurrence scenarios of a burned landscape. The development of transferable models is very important as they may reduce the cost of gathering data within mega-fires (burned area $>10,000$ ha; Stephens et al., 2014), in the context of post-fire decision-making (Latif et al., 2016), and also support management decisions when large data deficiencies exist in some portions of the area being surveyed (Clark et al., 2001). Model transferability can be assessed by determining whether a model calibrated under a given set of conditions (reference system) can successfully provide accurate predictions under different conditions (target system; Sequeira et al., 2018). Nevertheless, model transferability may be hindered by different constraints such as study design, species traits, model type and/or input data (Yates et al., 2018; Werkowska et al., 2017; Jiménez-Alfaro et al., 2018; Sequeira et al., 2018). Particularly relevant are: (a) sampling bias in the reference system (Barnes et al., 2014; Tsalyuk et al., 2017); (b) non-appropriate model algorithm and model overfitting
(Wenger et al., 2011; Sequeira et al., 2018); (c) non-stationarity of the ecological relationships (Osborne, Foody, \& Suárez-Seoane, 2007; Whittingham et al., 2007; Suárez-Seoane et al., 2014; FernándezGuisuraga et al., 2019a); or (d) non-analogous conditions in the target system (Thuiller et al., 2004). The evaluation of model transferability must deal with these constraints in order to improve analysis performance and provide a reliable tool to support resource management (Yates et al., 2018; Sequeira et al., 2018).

Recent developments in geospatial technologies have promoted the use of remote-sensing-derived products (Poursanidis et al., 2017), which represent a great opportunity, together with field data gathering, to evaluate vegetation recovery in large burned landscapes (Fernández-Manso et al., 2016; Fernández-Guisuraga et al., $2019 b)$. The use of high or very high spatial resolution imagery provided by space-borne sensors, such as Sentinel-2 (spatial resolution of 10-20-60 m) or WorldView-2 (spatial resolution of $2 \mathrm{~m}$ ), represents a great advance in vegetation recovery monitoring in areas of high spatial heterogeneity (Meng et al., 2017). In this sense, image texture analysis applied to remote-sensing data (Pu \& Cheng, 2015) has been proven to be a useful proxy of vegetation structure parameters in heterogeneous burned landscapes, such as species richness (Viedma et al., 2012) or vegetation biomass (Kelsey \& Neff, 2014), height (Fernández-Guisuraga et al., 2019b) and cover (FernándezGuisuraga et al., 2019a). Since the horizontal and vertical structure of vegetation influences canopy reflectance (Thenkabail et al., 2011; Buchhorn et al., 2013), the performance of post-fire recovery models is expected to vary across burned areas where different fire recurrence scenarios coexist and, therefore, where community composition may differ according to species regenerative traits.

Although the transferability of ecological models is a subject of particular research interest in fire ecology (Yates et al., 2018; Werkowska et al., 2017), only a few studies have addressed the transferability of either burn severity models (Fernández-García et al., 2018) or post-fire vegetation recovery models (FernándezGuisuraga et al., 2019a) based on remote-sensing products. The transferability of post-fire vegetation cover models between fire recurrence scenarios in burned ecosystems can fill knowledge gaps, providing reliable insights to support post-fire decision-making in the most efficient way (Yates et al., 2018; Sequeira et al., 2018).

In this study, we aim to evaluate the transferability of remote-sensing-based recovery models between fire recurrence scenarios at different spatial resolutions within two fire-prone pine ecosystems of the western Mediterranean Basin with different environmental characteristics. In particular, we aim to answer the following questions: (a) could model transferability be influenced by fire regime and, therefore, by community species composition within two burned landscapes with different environmental characteristics; and (b) does the spatial resolution of the remote-sensing products used to feed the models constrain model transferability between fire recurrence scenarios? We expect that fire recurrence would modify the community composition given the species' adaptive traits to fire regime (Pausas \& Keeley, 2014; Lloret et al., 2005; Taboada et al., 2018). Therefore, model transferability would 
perform better between fire recurrence scenarios with more sim-

6 ilar community composition (Thomas \& Vesk, 2017). Furthermore, we hypothesize that fine-grained remote-sensing products would offer a better performance than coarser products under heterogeneous recovery patterns of fire-prone ecosystems (Schoennagel et al., 2008). In these ecosystems, we expect that high-resolution products would capture at best ground local variations and complex ecological processes (Heinänen et al., 2012), improving model transferability (Sequeira et al., 2018).

\section{2 | METHODS}

\section{1 | Study area}

The study sites are located within the perimeter of two full standreplacing mega-fires which occurred in summer 2012 in Spain (Figure 1).

The first site (Sierra del Teleno wildfire; Figure 1, A) is located in NW Spain within a burned area of 11,602 ha predominantly covered by a Pinus pinaster forest stand. The pine canopy was almost consumed by fire and the burned stands were salvage-logged (Taboada et al., 2018). The study site is located at an average altitude of $1,063 \mathrm{~m}$ a.s.l. The relief is dominated by quartzite crests, large valleys with moderate slopes and sedimentary plains. It is an Atlantic-Mediterranean transition climatic zone with an average annual rainfall of around $650 \mathrm{~mm}$ and an average annual temperature of $10^{\circ} \mathrm{C}$, with a moderate summer drought ( $<2$ months). Soils are predominantly acidic with a sandy texture. Vegetation cover in post-fire conditions is mainly constituted by Pinus pinaster Aiton seedlings, obligate seeder shrub species, such as Halimium lasianthum subsp. alyssoides (Lam.) Greuter, Erica umbellata L. and Calluna vulgaris (L.) Hull, as well as resprouter shrubs, such as Pterospartum tridentatum
(L.) Willk. and Erica australis L. In the study area, these evergreen species reach the peak of their above-ground biomass in June and July.

The second site (Cortes de Pallás wildfire; Figure 1, B) is located in eastern Spain, within a megafire of 29,752 ha that completely consumed a Pinus halepensis Mill. and a Pinus pinaster stand. The altitude in the study site ranges between 114 and $995 \mathrm{~m}$ a.s.l. with steep slopes being present. Soils are predominantly basic with a sedimentary origin. The conditions in the region are typically Mediterranean, with an average annual rainfall of around $280 \mathrm{~mm}$, an average annual temperature of $16^{\circ} \mathrm{C}$ and three months of summer drought. Post-fire vegetation cover is constituted by Pinus pinaster and Pinus halepensis regeneration stands in a seedling growth stage, obligate seeder shrubs, such as Ulex parviflorus Pourr. and Rosmarinus officinalis L., as well as resprouter shrubs, such as Quercus coccifera $\mathrm{L}$. The peak of the growing season of these evergreen species is reached in May and June in the study area.

In both study sites, fire recurrence (number of wildfires) was estimated using a temporal series of Landsat imagery for the period 1978-2012. Recurrence values ranged between one and three (R1, R2 an R3; Fernández-García et al., 2019; Figure 1).

See Appendix S1 for a detailed list of tree and shrub species of each study site, including their growth form, regenerative traits and cover by fire recurrence scenario.

\section{2 | Field data sampling}

Four years after the wildfires, in spring-summer 2016, we defined a framework of 3,000 ha in each study site, where we established two independent sets of field plots of $2 \mathrm{~m} \times 2 \mathrm{~m}$ (60 in Sierra del Teleno and 33 in Cortes de Pallás) and $30 \mathrm{~m} \times 30 \mathrm{~m}$ (56 in Sierra del Teleno and 30 in Cortes de Pallás). This framework was used to focus
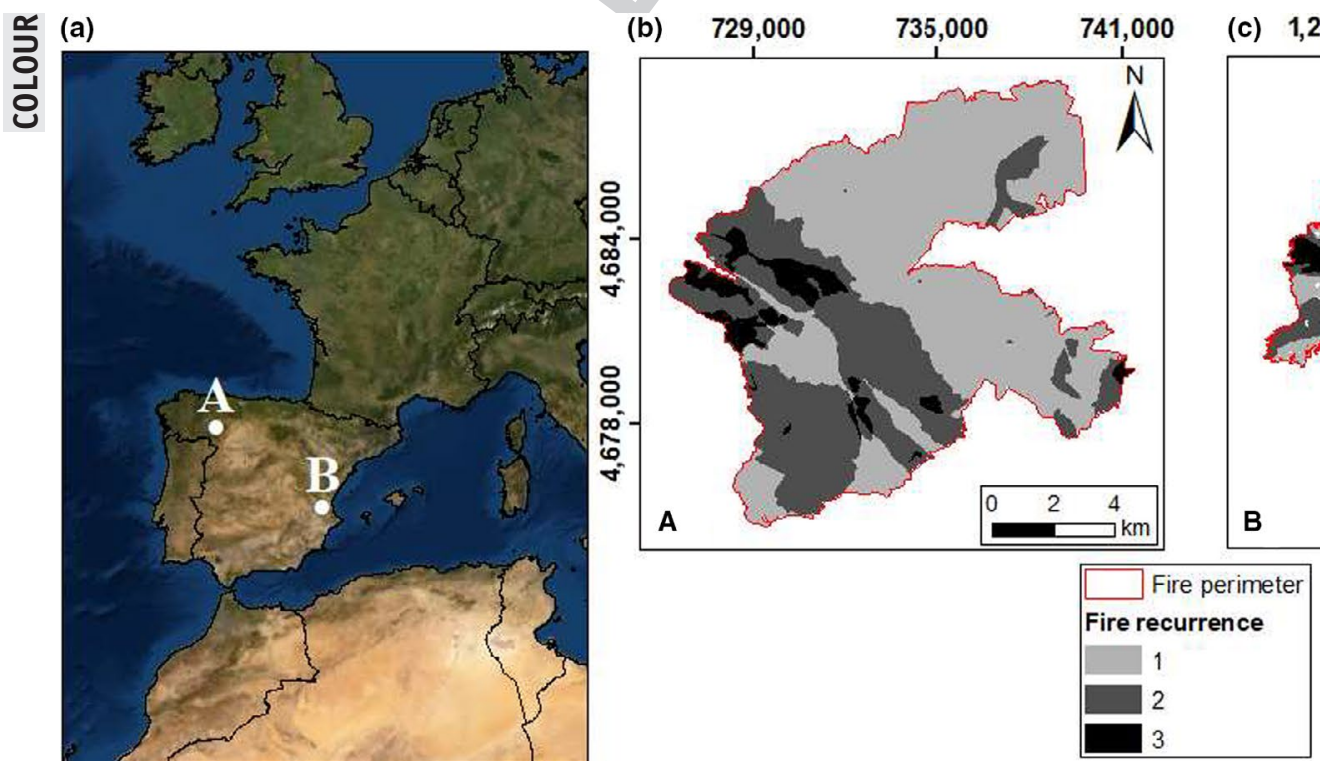

(c) $1,200,000 \quad 1,210,000 \quad 1,220,000$

FIGURE 1 Location (ESRI, 2019) (a) and fire recurrence (b and c) for the period 1978-2012 of Sierra del Teleno (A) and Cortes de Pallás (B) wildfires. Fire recurrence maps were computed through visual interpretation of Landsat imagery covering the study period 
the field sampling in areas dominated by pine ecosystems within the study areas (Fernández-García et al., 2019). Plots were distributed following a stratified design using the fire recurrence scenarios as strata. Thus, the number of plots for each recurrence scenario was proportional to the relative area affected by each class of fire recurrence in each study framework. In each plot we assessed, at different spatial scales, the vegetation cover during the peak above-ground biomass as one of the parameters of the community structure. In particular, we used a visual estimation method (Calvo et al., 2008) to quantify: (a) total vegetation cover percentage; (b) cover percentage of pine seedlings; (c) cover percentage by shrub species to obtain the cover of vegetation regenerative traits (obligate resprouters, obligate seeders and facultative seeders); and (d) woody debris cover percentage. Each field plot was georeferenced with a GPS receiver with $\mathrm{X}, \mathrm{Y}$ accuracy higher than $0.50 \mathrm{~m}$ in post-processing mode.

\section{3 | WorldView-2 and Sentinel-2 imagery and spectral products}

WorldView-2 scenes were acquired for the Sierra del Teleno wildfire on 23 June 2016 at 11:38:02 UTC and for Cortes de Pallás on 15 June 2016 at 11:12:48 UTC. Cloud cover was lower than 0.3\% in both scenes. The spatial resolution of the WorldView-2 multispectral sensor at nadir is $1.84 \mathrm{~m}$, but the image was resampled to $2 \mathrm{~m}$ by the image provider. This sensor captures data along eight bands in the visible and near infrared (NIR) region: B1, coastal blue (400$450 \mathrm{~nm}$ ); B2, blue ( $450-510 \mathrm{~nm}$ ); B3, green (510-580 nm); B4, yellow (585-625 nm); B5, red (630-690 nm); B6, red edge (705-745 nm); B7, NIR1 (770-895 nm) and B8, NIR2 (860-1,040 nm; Appendix S2). WorldView-2 scenes were orthorectified with rational polynomial coefficients delivered with the image metadata, as well as with a Digital Elevation Model (DEM) with a spatial resolution of $5 \mathrm{~m}$ and an accuracy higher than $20 \mathrm{~cm}$ in Z, provided by the Spanish National Center of Geographic Information (http://www.cnig.es/). The scenes were atmospherically corrected to surface reflectance with the Fast Line-of-sight Atmospheric Analysis of Spectral Hypercubes algorithm (FLAASH; Matthew et al., 2003) implemented in ENVI 5.3 software (https://www.harrisgeospatial.com/).

Sentinel-2 MSI Level 1C imagery was acquired for Sierra del Teleno wildfire from the Copernicus Open Access Hub (https://scihub.copernicus.eu/) on 5 August 2016 at 11:12:45 UTC and for Cortes de Pallás on 30 July 2016 at 10:53:38 UTC, both scenes being cloud cover-free. Sentinel- 2 has thirteen bands at different spatial resolution over the visible, NIR and short wave IR (SWIR) regions: $10-\mathrm{m}$ spatial resolution bands (B2 blue, 458-523 nm; B3 green, 543-578 nm; B4 red, $650-680 \mathrm{~nm}$ and B8 NIR, 785-899 nm); 20-m spatial resolution bands (B5 red edge 1, 698-713 nm; B6 red edge 2, 733-748 nm; B7 red edge 3, 773-793 nm; B8a narrow NIR, 855-875 nm; B11 SWIR1, 1,565-1,655 nm and B12 SWIR2, 2,100-2,280 nm); and 60-m spatial resolution bands (B1 coastal blue, 432-453 nm; B9 water vapor, 935$955 \mathrm{~nm}$, B10 cirrus, 1,358-1,389 nm; Appendix S2). Sentinel-2 bands were resampled to $20 \mathrm{~m}$ using a nearest neighbor rule. Sentinel-2 MSI
Level $1 \mathrm{C}$ imagery was already orthorectified by the supplier and the scenes were then only atmospherically corrected to surface reflectance with the FLAASH algorithm.

We computed two second-order texture features (mean and variance; Appendix S3) for each surface reflectance band of the processed WorldView-2 and Sentinel-2 imagery using a moving window of $3 \times 3$ pixels and the Gray Level Co-Occurrence Matrix (GLCM; Haralick et al., 1973). The texture features and window size were chosen based on previous research carried out in burned landscapes of high spatial heterogeneity (Fernández-Guisuraga et al., 2019a). Each texture was averaged for the four spatial directions to gather directionally invariant texture measures (Zhang \& Xie, 2012). Texture values were extracted for each field plot location to be used as predictors of vegetation cover.

\subsection{Data analysis}

A permutational multivariate analysis of variance (PERMANOVA) and a principal components analysis (PCA) were used to explore, within each study site, the multivariate associations between vegetation community composition (cover of vegetation regenerative traits, pine seedlings and woody debris) and fire recurrence. Then, the effects of fire recurrence on each specific community variable were analyzed through an analysis of variance (ANOVA) followed by a pairwise multiple comparison of means (Scheffe test). These analyses were performed using R (R Core Team, 2017) and the 'vegan' package ( $R$ Core Team, R Foundation for Statistical Computing, Vienna, Austria).

For its part, a correlation analysis was conducted in order to discard potential multicollinearity problems among the spectral predictors (second-order texture features, mean and variance) of vegetation cover. Bivariate Pearson correlations allowed for identifying groups of strongly correlated predictors $\left(r_{\text {Pearson }}>|0.7|\right)$. The predictor with the highest biophysical meaning within each group was preserved for further analyses (Fernández-Guisuraga et al., 2019b).

Vegetation cover model transferability between fire recurrence scenarios was assessed by means of Random Forest (RF) regression models (Breiman, 2001) based on WorldView-2 and Sentinel-2 spectral predictors. RF is a machine-learning algorithm based on classification and regression trees (CART; Oliveira et al., 2012). It is insensitive to noisy datasets and makes no assumptions about the distribution of the response variable (Iqbal et al., 2018). For each site, fire recurrence scenario and spatial resolution, we built a model of total vegetation cover. RF fits an ensemble of random binary trees to the data, each tree being generated by bootstrap samples (Breiman, 2001; Hong et al., 2018; Iqbal et al., 2018). Each split of the tree is defined using a random subset of the predictors at each node or sample (Oliveira et al., 2012). The final output is the average of the results of every tree (Breiman, 2001). The value of the model parameter mtry (number of variables for each tree split) was set using the function tuneRF (Liaw \& Wiener, 2002). This function searches below and above the default value of mtry (number of predictors/3) to find the value with the 
minimum error estimate (Liaw \& Wiener, 2002; Oliveira et al., 2012). The value of the model parameter ntree (number of trees) was set to 1,000 to obtain stable predictions (Oshiro et al., 2012; Probst \& Boulesteix, 2018). Predictor importance in the model was evaluated by means of the percentage increase in mean square error (\%IncMSE), which represents the decrease in model accuracy if a variable is dropped from the model. The final model was obtained by averaging one hundred replicate RF models in order to produce stable model outputs (García-Llamas et al., 2019). A parsimonious subset of predictors for each fire recurrence scenario, spatial resolution and site was selected through a forward model selection technique (see Kane et al., 2015 and García-Llamas et al., 2019 for more details). The variance explained by the models (pseudo- $R^{2}$ ) was calculated using the internal out-of-bag error rate (Liaw \& Wiener, 2002).

Vegetation cover models calibrated in a particular fire recurrence scenario (reference system) were validated in the other scenarios (target systems) within each study site, iteratively. For instance, the spatial output of a model calibrated in scenario R1 was validated using data from scenarios R2 and R3 across the same wildfire. Model transferability performance was assessed using the root mean square error (RMSE; Equation 1) in percent cover.

$$
\operatorname{RMSE}(\% \text { cover })=\sqrt{\frac{\sum_{i=1}^{n}\left(P_{i}-O_{i}\right)^{2}}{n}}
$$

where $O_{i}$ are observed vegetation cover values in the target system, $P_{i}$ are the predicted vegetation cover values obtained by applying the RF model of the reference system to the target system, and $n$ corresponds to the number of field plots in the target system.

Random Forest (RF) regression was applied using R ( $R$ Core Team, 2017) and the 'RandomForest' package (Liaw \& Wiener, 2002).

\section{3 | RESULTS}

The community species composition showed a non-stationary response regarding the species' regenerative traits between fire recurrence scenarios in the Sierra del Teleno (PERMANOVA $F=95.94$; $p<0.01)$ and Cortes de Pallás $(F=32.02 ; p<0.01)$ wildfires. The first (Dim1) and second (Dim2) PCA axes explained $64.3 \%$ and $17.6 \%$ respectively of the variance in the Sierra del Teleno wildfire and $42.7 \%$ and $23.2 \%$ respectively in Cortes de Pallás. In the Sierra del Teleno wildfire, resprouter shrub species dominated over obligate seeder shrubs under high fire recurrence (R2 and R3). The opposite pattern was observed for the lowest recurrence scenario (R1), characterized by a higher cover of obligate seeders (shrubs and pine seedlings) and woody debris. Meanwhile, in the Cortes de Pallás wildfire, R1 and R2 fire recurrence scenarios were associated with a high cover of obligate seeders, the resprouters being the dominant shrub species in fire recurrence scenario R3 (Figure 2). In both study sites, resprouter cover tended to increase significantly $(p<0.01)$ with fire recurrence (R2 and R3 in the Sierra del Teleno wildfire and R3 in Cortes de Pallás), the seeder shrubs exhibiting the inverse pattern. For its part, there was a significant reduction $(p<0.01)$ in pine seedling regeneration within high fire recurrence scenarios (R2 and R3) in both study sites. Furthermore, the accumulation of woody debris was significantly higher $(p<0.01)$ under the low fire recurrence scenario (R1) in both wildfires (Figure 3).

The highest variance of total vegetation cover was explained by RF models under high fire recurrence scenarios (R2 and R3) for both study sites and sensors (Table 1). Model performance was better in the Sierra del Teleno wildfire than in Cortes de Pallás. The explained variance of the total vegetation cover was higher using WorldView-2 than Sentinel-2 textures as predictors (Table 1). For their part, the most parsimonious models were calibrated with four or less predictors. Mean texture features, especially those computed from the red-edge region of the spectrum (B6 for WorldView-2 and B5, B6 and B7 for Sentinel-2), were selected in almost all models (Table 1).

Model transferability error ranged between $5 \%$ and $35 \%$ in the Sierra del Teleno wildfire and between $13 \%$ and $32 \%$ in the Cortes de Pallás wildfire. Models calibrated with fine-grained satellite image texture exhibited the lowest transferability error. The best model transferability in the Sierra del Teleno wildfire was achieved between the areas affected by two and three fires (RMSE around $5 \%$, using WorldView-2 textures as predictors). By contrast, in the Cortes de Pallás wildfire, the areas affected by one and two fires featured the lowest error in the transferability approach (RMSE around $15 \%$ for both remote sensing data; Figure 4).

\section{4 | DISCUSSION}

Predictive models have become essential tools in fire ecology (Pausas \& Lloret, 2007; Canelles et al., 2019) due to increasing social
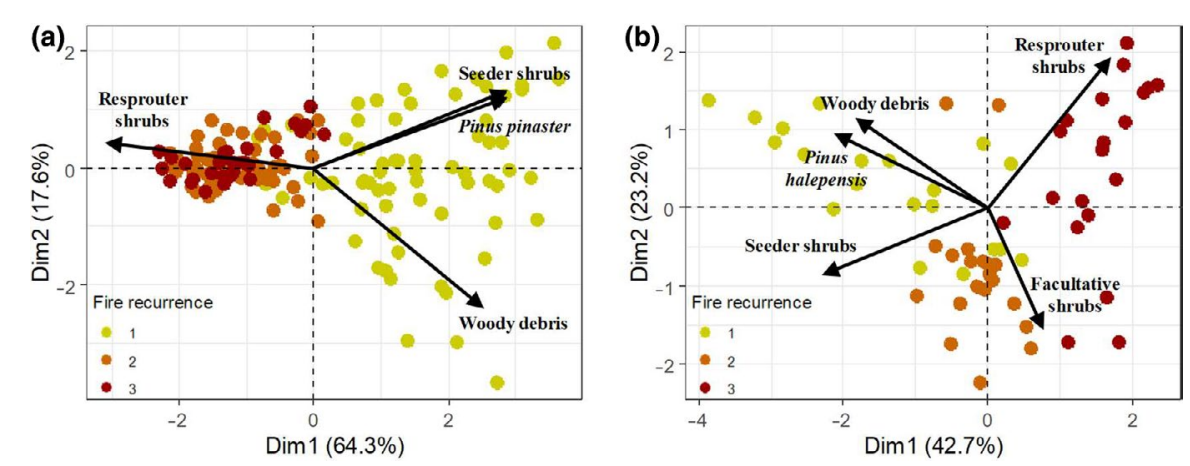

FIGURE 2 Principal components analysis (PCA) biplots of vegetation community composition, showing the distribution of the field plots under different fire recurrence scenarios (one, two and three fires) for Sierra del Teleno (a) and Cortes de Pallás (b) wildfires 

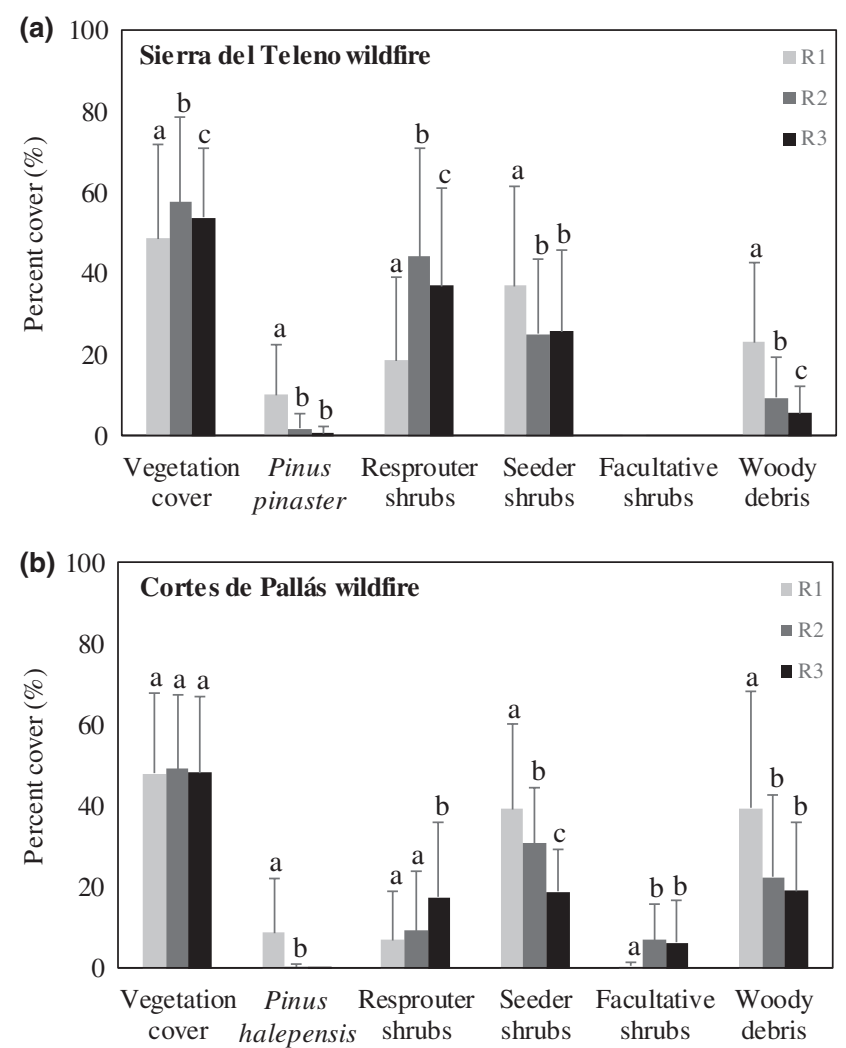

FIGURE 3 Mean cover and standard deviation of the community assemblage under one (R1), two (R2) and three (R3) number of fires in Sierra del Teleno (A) and Cortes de Pallás (B) wildfires. The letters located above the standard deviation bars ( $a$, $\mathrm{b}$ and c) denote statistically significant differences between means $(p<0.05)$. Data were collected in $2 \mathrm{~m} \times 2 \mathrm{~m}$ field plots

and scientific awareness about the consequences of global change regarding fire regime parameters (Fernández-García et al., 2019). There is a growing interest in the attainment of transferable ecological models to support anticipatory predictions instead of explanatory models (Yates et al., 2018) to enhance the efficiency of post-fire management actions, which are broadly context-dependent
(Taboada et al., 2017; Fernández-Guisuraga et al., 2019a). The main novelty of this study lies in the evaluation of the remote-sensing potential at different spatial scales together with field measurements using a machine-learning approach to obtain transferable vegetation recovery models between areas affected by different fire recurrence for the case of two large burned areas with different climatic conditions. Our results highlighted the relevance of choosing the appropriate spatial resolution of remote-sensing products to be used as predictors in the proposed scheme. Models were transferable between fire recurrence scenarios in both study sites (RMSE lower than 35\%), although the best results were obtained between scenarios with more similar community composition (RMSE of around 15\% or lower) owing to the species' regenerative traits in responce to the disturbance regime and therefore have a stronger spectral similarity.

\section{1 | Fire recurrence influence on community structure and composition}

The relative abundance of woody understorey species, grouped according to their regenerative traits, and pine seedlings, varied with fire recurrence both in the Sierra del Teleno and Cortes de Pallás wildfires. We found that resprouter abundance tended to increase under high fire recurrence scenarios in both study sites. This could be attributable to the maximization of resprouter fitness by the resource allocation to above-ground or below-ground fire-resistant structures (Pausas \& Vallejo, 1999; Knox \& Morrison, 2005). In addition, the relative abundance of obligate seeder shrubs decreased under high fire recurrence scenarios, since they may not have become reproductively mature to produce a viable canopy or soil seed bank in the fire-free period (Pausas \& Keeley, 2014; Lloret et al., 2005). For its part, the dominance of obligate seeder shrubs in the Mediterranean site, especially in areas of low recurrence, could be attributed to their seed germination stimulated by fire (Pausas \& Vallejo, 1999; Pausas \& Keeley, 2014; Taboada et al., 2018) and more tolerance to water deficit than resprouter shrubs during summer droughts (Pausas et al., 2004).

\begin{tabular}{|c|c|c|c|c|}
\hline & \multicolumn{2}{|l|}{ WV-2 } & \multicolumn{2}{|l|}{ S-2 } \\
\hline & Predictors & $\begin{array}{l}\text { Variance } \\
\text { (\%) }\end{array}$ & Predictors & $\begin{array}{l}\text { Variance } \\
\text { (\%) }\end{array}$ \\
\hline \multicolumn{5}{|c|}{ Sierra del Teleno wildfire } \\
\hline $\mathrm{R} 1$ & Mean(B1,B3,B6), var(B6) & 45.04 & Mean(B1,B8A), var(B5) & 25.32 \\
\hline $\mathrm{R} 2$ & Mean(B6), var(B6) & 51.18 & Mean(B5), $\operatorname{var}(B 3, B 5, B 8 A)$ & 39.12 \\
\hline R3 & Mean(B3), $\operatorname{var}(\mathrm{B} 3, \mathrm{~B} 6)$ & 56.79 & Mean(B12), var(B1,B5) & 35.23 \\
\hline \multicolumn{5}{|c|}{ Cortes de Pallás wildfire } \\
\hline R1 & Mean(B3), $\operatorname{var}(\mathrm{B} 6)$ & 37.74 & Mean(B12), var(B8A) & 22.60 \\
\hline $\mathrm{R} 2$ & Mean(B1,B3) & 50.32 & Mean(B8A,B12) & 34.76 \\
\hline R3 & Mean(B3,B6) & 41.44 & Mean(B5,B12) & 30.57 \\
\hline
\end{tabular}

TABLE 1 Mean explained variance of the one hundred Random Forest (RF) iterations for the most parsimonious models of vegetation cover for Sierra del Teleno and Cortes de Pallás wildfires using WorldView-2 (WV-2) and Sentinel-2 (S-2) mean and variance (var) textures as spectral predictors for areas burned one (R1), two (R2) and three (R3) times

The standard deviation of the explained variance of the RF iterations for each model was $<1 \%$. WV-2 bands B1, B3 and B6 correspond to coastal blue, green and red edge spectral regions, respectively. Accordingly, S-2 bands B1, B3, B5, B8A and B12 correspond to coastal blue, green, red edge, NIR and SWIR spectral regions. 


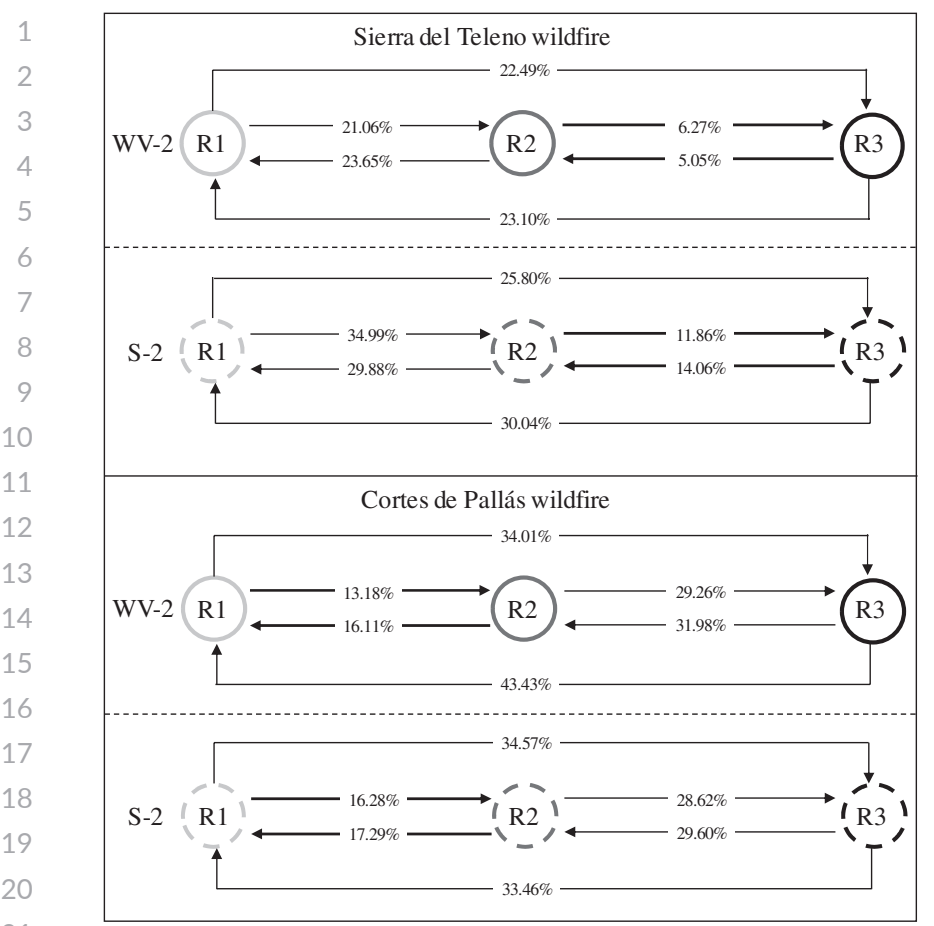

21
FIGURE 4 Mean model transferability performance (root mean square error [RMSE]) of the one hundred Random Forest (RF) iterations between one (R1), two (R2) and three (R3) fire recurrence scenarios in the Sierra del Teleno and Cortes de Pallás wildfires using WorldView-2 (WV-2) and Sentinel-2 (S-2) as spectral predictors. The thickest arrows correspond to model transferability errors of around $15 \%$ or lower. The standard deviation of the RMSE of the RF iterations for each model was less than $1 \%$

\section{2 | Predictive performance of remote- sensing data}

It has been demonstrated that woody debris accumulation decreased with increasing fire recurrence (Taboada et al., 2018; FernándezGarcía et al., 2019). The highest model performance under high fire recurrence scenarios could be explained, in both wildfires, by the lower background influence of non-photosynthetic vegetation, such as woody debris, on the spectral signature of healthy vegetation (Montandon \& Small, 2008; Schile et al., 2013) in comparison to areas burned once. Fernández-Guisuraga et al. (2019b) also found the same pattern using a different modeling approach in a fireprone ecosystem. Despite both study sites presenting heterogeneous post-fire recovery patterns of the vegetation, the narrower environmental variation and, therefore, the more homogeneous landscape of Sierra del Teleno, in comparison with Cortes de Pallás (Fernández-Guisuraga et al., 2019a), may have led to improved model performance in the former site. In this regard, the high spatial variation of ground cover in both study sites requires the use of remotesensing data at very high spatial resolution, such as those captured by WorldView-2, to obtain the best modeling results (Meng et al., 2017). The ground heterogeneity of fire-prone ecosystems cannot be captured properly by coarse spatial resolution satellite imagery (Wood et al., 2012) containing single pixel spectra from different ground features (Stefanov \& Netzband, 2005; Xiao \& Moody, 2005), which is known as the land cover aggregation effect (Munyati \& Mboweni, 2013). For their part, texture features have been proven to be adequate remote-sensing products to model post-fire vegetation structure in fire-prone landscapes, as observed in several studies (Viedma et al., 2012; Gu et al., 2013; Fernández-Guisuraga et al., 2019b). In areas of high spatial heterogeneity, texture analysis optimizes the spatial information characterization, since it accounts for both the pixel reflectance values and the spatial variation of these values between adjacent pixels (Fernández-Guisuraga et al., 2019a, 2019b). Accordingly, image texture is highly sensitive in these areas to variations in vegetation structural parameters, such as leaf area index, canopy cover, height and density or vertical and horizontal heterogeneity (Sarker \& Nichol, 2011; Wood et al., 2012) than other satellite products, such as raw reflectance data or spectral indices (Sarker \& Nichol, 2011; Eckert, 2012; Fernández-Guisuraga et al., 2019b). Therefore, vegetation cover could be characterized by texture metrics in each fire recurrence scenario, with explained the variances around or higher than $40 \%$ using WorldView-2 texture predictors. The contribution of textures from the red-edge region of the electromagnetic spectrum to the vegetation cover modeling in both wildfires is worth mentioning. In areas with heterogeneous ground cover, high red-edge sensitivity to shifts in vegetation biophysical parameters, such as chlorophyll content or biomass density (Xie et al., 2018), have led to a better model performance within each study site. Additionally, the red-edge region is quite efficient to discriminate the vegetation spectral signal from background features (Schumacher et al., 2016).

\section{3 | Transferability}

Despite the potential of remote-sensing data to predict vegetation structure parameters at individual sites (Foody et al., 2003; Cutler et al., 2012; Fernández-Guisuraga et al., 2019b), the attainment of transferable models as a cost-effective tool for land management decision-making remains challenging (Tsalyuk et al., 2017; Sequeira et al., 2018). The spatial variability of vegetation responses, along with field data collection and uncertainties related to satellite imagery pre-processing, may hinder the transferability of remote-sensing-based vegetation models between different areas (Tsalyuk et al., 2017; Regos et al., 2019).

Our results supported the hypothesis that species' regenerative traits had a significant impact on model transferability performance because these traits reflect the species' response to the disturbance regime and, therefore, their distribution and abundance (Syphard \& Franklin, 2010; Street et al., 2015; Regos et al., 2019). A specific species assemblage as a result of plants' regenerative traits features a characteristic spectral profile arising from the phenology and physiological characteristics of the species (Ustin \& Gamon, 2010), as well as from the structural layering and multiple scattering between different species (Verrelst et al., 2009). Hence, vegetation cover models for both wildfires exhibited the highest transferability between 
burned areas with a more similar vegetation community composition (regarding the relative abundance of seeder and resprouter species) and spectral response. These scenarios corresponded to areas burned two and three times in the Sierra del Teleno wildfire and areas burned once and twice in Cortes de Pallás during the considered time period. Under these scenarios, the stationary vegetation responses enabled the modeled relationships between plant community composition and remote-sensing data to be kept relatively constant (FernándezGuisuraga et al., 2019a), therefore obtaining a good performance (RMSE of around $15 \%$ or lower, and even as low as 5\%) of the model transferability approach (Maguire et al., 2016; Osborne \& SuárezSeoane, 2002; Sequeira et al., 2018). In less favorable transferability schemes, the performance was still acceptable (RMSE lower than $35 \%)$, probably because the spectral response dissimilarity between the reference and target systems (non-analogous conditions) arising from vegetation non-stationary responses was not high enough to produce truncation in the model calibration (Yates et al., 2018; Regos et al., 2019; Fernández-Guisuraga et al., 2019a).

The spatial resolution of remote-sensing data had a significant impact on model transferability performance in both study sites. As expected, vegetation cover models calibrated with WorldView-2's finegrained satellite texture exhibited the lowest transferability error. In landscapes with great spatial heterogeneity, the use of remote-sensing data at very high spatial resolution is advisable because it captures better the variability of the ground cover pattern, allowing better transferability of the modeled relationships between sites (FernándezGuisuraga et al., 2019b). Another probable explanation for the satisfactory results in the transferability approach could be related to the use of parsimonious models calibrated from few predictors (Wenger $\&$ Olden, 2012), since complex models could lead to model overfitting and, therefore, predictions cannot be adequately transferred to the target area (Yates et al., 2018; Bell \& Schlaepfer, 2016). Likewise, modeled relationships must be transferred to the target area using remote-sensing data acquired during the same phenological stage of the vegetation in which the relationships were calibrated in the reference area. In both study sites, the field-sampling campaign and, consequently, the model calibration in the reference areas were conducted during the peak of green biomass in spring/summer to minimize the effect of non-photosynthetic vegetation to the modeled relationships (Wehlage et al., 2016; Jansen et al., 2018). Although only the RF regression modeling approach was tested in our study, it has been reported to provide a good performance in ecological modeling transferability (Cutler et al., 2007). However, the inability of RF regression to predict beyond the data range used for model calibration (Iqbal et al., 2018; Sequeira et al., 2018) may require the collection of field data covering a wider variability range to avoid non-analogous conditions.

\section{5 | CONCLUSIONS}

1. Fire recurrence is a major driver of both community structure and composition in fire-prone ecosystems of the Mediterranean Basin with different environmental characteristics.
2. Species responses to the disturbance regime have a large impact on the performance of vegetation cover model transferability analysis. The best transferability results are achieved between fire recurrence scenarios driving to similar vegetation community composition regarding the balance of plants' regenerative traits. Under these scenarios, the relationship between community composition and remote-sensing data is consistent because of the stationarity of the species responses.

3. The ground spatial heterogeneity of fire-prone ecosystems severely affects vegetation cover modeling based on remote-sensing data. In these ecosystems, the vegetation spectra may be highly influenced by background signal, requiring the use of very high spatial resolution instead of coarse satellite imagery to properly characterize the vegetation cover. Also, the performance of model transferability analysis is highly influenced by the spatial resolution of remotesensing data used as predictors of vegetation cover.

4. The framework proposed in this research paper would presumably allow land managers to reduce efforts in data collection in the context of post-fire decision-making to assess vegetation recovery within large burned ecosystems with fire regime variability.

\section{ACKNOWLEDGEMENTS}

This study was financially supported by the Spanish Ministry of Economy and Competitiveness, and the European Regional Development Fund (ERDF), in the framework of the GESFIRE (AGL2013-48189-C2-1-R) and FIRESEVES (AGL2017-86075-C2$1-R)$ projects; and by the Regional Government of Castilla y León in the framework of the FIRECYL (LE033U14) and SEFIRECYL (LE001P17) projects. JMFG is supported by a predoctoral fellowship from the Spanish Ministry of Education (FPU16/03070).

\section{CONFLICT OF INTEREST}

The authors declare no conflicts of interest.

\section{AUTHOR CONTRIBUTIONS}

SSS and LC conceived the research idea and designed the study; JMFG, SSS and LC collected data; JMFG performed statistical analyses and wrote the first draft of the manuscript with contributions from SSS and LC; SSS and LC revised the draft, improved the text and gave final approval for publication.

\section{DATA AVAILABILITY STATEMENT}

The data for this publication are stored in the internal database of the Applied Ecology and Remote Sensing research group in the University of León. The raw data used in this manuscript will be available from the corresponding author upon request.

\section{ORCID}

Susana Suárez-Seoane (iD https://orcid.org/0000-0001-7656-4214

\section{REFERENCES}

Barnes, M.A., Jerde, C.L., Wittmann, M.E., Chadderton, W.L., Ding, 8 J., Zhang, J. et al (2014) Geographic selection bias of occurrence 
data influences transferability of invasive Hydrilla verticillata distribution models. Ecology and Evolution, 4, 2584-2593. https://doi. org/10.1002/ece3.1120

Bell, D.M. and Schlaepfer, D.R. (2016) On the dangers of model complexity without ecological justification in species distribution modeling. Ecological Modelling, 330, 50-59. https://doi.org/10.1016/j.ecolm odel.2016.03.012

Breiman, L. (2001) Random forests. Machine Learning, 45, 5-32. https:// doi.org/10.1023/A:1010933404324

Buchhorn, M., Walker, D.A., Heim, B., Raynolds, M.K., Epstein, H.E. and Schwieder, M. (2013) Ground-based hyperspectral characterization of Alaska Tundra vegetation along environmental gradients. Remote Sensing, 5, 3971-4005. https://doi.org/10.3390/rs508 3971

Calvo, L., Santalla, S., Valbuena, L., Marcos, E., Tárrega, R. and LuisCalabuig, E. (2008) Post-fire natural regeneration of a Pinus pinaster forest in NW Spain. Plant Ecology, 197, 81-90. https://doi. org/10.1007/s11258-007-9362-1

Canelles, Q., Aquilué, N., Duane, A. and Brotons, L. (2019) From stand to landscape: modelling post-fire regeneration and species growth. Ecological Modelling, 404, 103-111. https://doi.org/10.1016/j.ecolm odel.2019.05.001

Clark, J.S., Carpenter, S.R., Barber, M., Collins, S., Dobson, A., Foley, J.A. et al (2001) Ecological forecasts: An emerging imperative. Science, 293, 657-660. https://doi.org/10.1126/science.293.5530.657

Collins, L., Griffioen, P., Newell, G. and Mellor, A. (2018) The utility of Random Forests for wildfire severity mapping. Remote Sensing of the Environment, 216, 374-384. https://doi.org/10.1016/j. rse.2018.07.005

Cutler, D.R., Edwards, T.C., Beard, K.H., Cutler, A., Hess, K.T., Gibson, J. et al (2007) Random forests for classification in ecology. Ecology, 88, 2783-2792. https://doi.org/10.1890/07-0539.1

Cutler, M.E.J., Boyd, D.S., Foody, G.M. and Vetrivel, A. (2012) Estimating tropical forest biomass with a combination of SAR image texture and Landsat TM data: An assessment of predictions between regions. ISPRS Journal of Photogrammetry and Remote Sensing, 70, 66-77. https://doi.org/10.1016/j.isprsjprs.2012.03.011

Eckert, S. (2012) Improved forest biomass and carbon estimations using texture measures from WorldView-2 satellite data. Remote Sensing, 4, 810-829. https://doi.org/10.3390/rs4040810

ESRI (2019) ArcGIS Online. Retrieved from https://esri.maps.arcgis.com/ home/index.html

Fernández-García, V., Santamarta, M., Fernández-Manso, A., Quintano, C., Marcos, E. and Calvo, L. (2018) Burn severity metrics in fireprone pine ecosystems along a climatic gradient using Landsat imagery. Remote Sensing of Environment, 206, 205-217. https://doi. org/10.1016/j.rse.2017.12.029

Fernández-García, V., Fulé, P.Z., Marcos, E. and Calvo, L. (2019) The role of fire frequency and severity on the regeneration of Mediterranean serotinous pines under different environmental conditions. Forest Ecology and Management, 444, 59-68. https://doi.org/10.1016/j. foreco.2019.04.040

Fernández-Guisuraga, J.M., Calvo, L., Fernández-García, V., MarcosPorras, E., Taboada, A. and Suárez-Seoane, S. (2019a) Efficiency of remote sensing tools for post-fire management along a climatic gradient. Forest Ecology and Management, 433, 553-562. https://doi. org/10.1016/j.foreco.2018.11.045

Fernández-Guisuraga, J.M., Suárez-Seoane, S. and Calvo, L. (2019b) Modeling Pinus pinaster forest structure after a large wildfire using remote sensing data at high spatial resolution. Forest Ecology and Management, 446, 257-271. https://doi.org/10.1016/j. foreco.2019.05.028

Fernández-Manso, A., Quintano, C. and Roberts, D.A. (2016) Burn severity influence on post-fire vegetation cover resilience from Landsat MESMA fraction images time series in Mediterranean forest ecosystems. Remote Sensing of the Environment, 184, 112-123. https://doi.org/10.1016/j.rse.2016.06.015

Foody, G.M., Boyd, D.S. and Cutler, M.E.J. (2003) Predictive relations of tropical forest biomass from Landsat TM data and their transferability between regions. Remote Sensing of Environment, 85, 463-474. https://doi.org/10.1016/S0034-4257(03)00039-7

García-Llamas, P., Suárez-Seoane, S., Taboada, A., Fernández-Manso, A., Quintano, C., Fernández-García, V. et al (2019) Environmental drivers of fire severity in extreme fire events that affect Mediterranean pine forest ecosystems. Forest Ecology and Management, 433, 24-32. https://doi.org/10.1016/j.foreco.2018.10.051

Gu, Z., Ju, W., Li, L., Li, D., Liu, Y. and Fan, W. (2013) Using vegetation indices and texture measures to estimate vegetation fractional coverage (VFC) of planted and natural forests in Nanjing city, China. Advances in Space Research, 51, 1186-1194. https://doi.org/10.1016/j. asr.2012.11.015

Haralick, R.M., Shanmugam, K. and Dinstein, I.H. (1973) Textural features for image classification. IEEE Transactions on Systems, Man, and Cybernetics, 3, 610-621. https://doi.org/10.1109/ TSMC.1973.4309314

Heinänen, S., Erola, J. and von Numers, M. (2012) High resolution species distribution models of two nesting water bird species: a study of transferability and predictive performance. Landscape Ecology, 27, 545-555. https://doi.org/10.1007/s10980-012-9705-8

Hong, H., Tsangaratos, P., Ilia, J., Liu, J., Zhu, X. and Xu, C. (2018) Applying genetic algorithms to set the optimal combination of forest fire related variables and model forest fire susceptibility based on data mining models. The case of Dayu County. China. Science of the Total Environment, 630, 1044-1056. https://doi.org/10.1016/j.scito tenv.2018.02.278

Iqbal, F., Lucieer, A. and Barry, K. (2018) Poppy crop capsule volume estimation using UAS remote sensing and random forest regression. International Journal of Applied Earth Observation and Geoinformation, 73, 362-373. https://doi.org/10.1016/j.jag.2018.06.008

Jansen, V.S., Kolden, C.A. and Schmalz, H.J. (2018) The development of near real-time biomass and cover estimates for adaptive rangeland management using Landsat 7 and Landsat 8 surface reflectance products. Remote Sensing, 10, 1057. https://doi.org/10.3390/rs10071057

Jiménez-Alfaro, B., Suárez-Seoane, S., Chytrý, M., Hennekens, S.M., Willner, W., Hájek, M. et al (2018) Modelling the distribution and compositional variation of plant communities at the continental scale. Diversity and Distributions, 24, 978-990. https://doi.org/10.1111/ ddi.12736

Kane, V.R., Cansler, C.A., Povak, N.A., Kane, J.T., McGaughey, R.J., Lutz, J.A. et al (2015) Mixed severity fire effects within the Rim fire: Relative importance of local climate, fire weather, topography, and forest structure. Forest Ecology and Management, 358, 62-79. https:// doi.org/10.1016/j.foreco.2015.09.001

Keeley, J.E., Pausas, J.E., Rundel, P.W., Bond, W.J. and Bradstock, R.A. (2011) Fire as an evolutionary pressure shaping plant traits. Trends in Plant Science, 16, 406-411. https://doi.org/10.1016/j.tplan ts.2011.04.002

Kelsey, K.C. and Neff, J.C. (2014) Estimates of aboveground biomass from texture analysis of Landsat Imagery. Remote Sensing, 6, 64076422. https://doi.org/10.3390/rs6076407

Knox, K.J.E. and Morrison, D.A. (2005) Effects of inter-fire intervals on the reproductive output of resprouters and obligate seeders in the Proteaceae. Austral Ecology, 30, 407-413. https://doi. org/10.1111/j.1442-9993.2005.01482.x

Latif, Q.S., Saab, V.A., Hollenbeck, J.P. and Dudley, J.G. (2016) Transferability of habitat suitability models for nesting woodpeckers associated with wildfire. Condor, 118, 766-790. https://doi. org/10.1650/CONDOR-16-86.1

Liaw, A. and Wiener, M. (2002) Classification and regression by RandomForest. R News, 2, 18-22. 
Lloret, F., Estevan, H., Vayreda, J. and Terradas, J. (2005) Fire regenerative syndromes of forest woody species across fire and climatic gradients. Oecologia, 146, 461-468. https://doi.org/10.1007/ s00442-005-0206-1

Lozano, F.J., Suárez-Seoane, S., Kelly, M. and Luis-Calabuig, E. (2008) A multi-scale approach for modeling fire occurrence probability using satellite data and classification trees: A case study in a mountainous Mediterranean region. Remote Sensing of the Environment, 112, 708-719. https://doi.org/10.1016/j.rse.2007.06.006

Maguire, K.C., Nieto-Lugilde, D., Blois, J.L., Fitzpatrick, M.C., Williams, J.W., Ferrier, S. and et al (2016) Controlled comparison of speciesand community-level models across novel climates and communities. Proceedings of the Royal Society B, 283, 20152817. https://doi. org/10.1098/rspb.2015.2817

Matthew, M., Adler-Golden, S., Berk, A., Felde, G., Anderson, G., Gorodetzky, D. et al (2003) Atmospheric correction of spectral imagery: evaluation of the FLAASH algorithm with AVIRIS data. Proceedings of SPIE, 5093, 474-482. https://doi.org/10.1109/ AIPR.2002.1182270

Meng, R., Wu, J., Schwager, K.L., Zhao, F., Dennison, P.E., Cook, B.D. et al (2017) Using high spatial resolution satellite imagery to map forest burn severity across spatial scales in a Pine Barrens ecosystem. Remote Sensing of the Environment, 191, 95-109. https://doi. org/10.1016/j.rse.2017.01.016

Montandon, L.M. and Small, E.E. (2008) The impact of soil reflectance on the quantification of the green vegetation fraction from NDVI. Remote Sensing of Environment, 112, 1835-1845. https://doi. org/10.1016/j.rse.2007.09.007

Moreira, B., Tormo, J. and Pausas, J.G. (2012) To resprout or not to resprout: factors driving intraspecific variability in resprouting. Oikos, 121, 1577-1584. https://doi. org/10.1111/j.1600-0706.2011.20258.x

Munyati, C. and Mboweni, G. (2013) Variation in NDVI values with change in spatial resolution for semi-arid savanna vegetation: a case study in northwestern South Africa. International Journal of Remote Sensing, 34, 2253-2267. https://doi.org/10.1080/01431161.2012.743692

Oliveira, S., Oehler, F., San-Miguel-Ayanz, J., Camia, A. and Pereira, M.C. (2012) Modeling spatial patterns of fire occurrence in Mediterranean Europe using Multiple Regression and Random Forest. Forest Ecology and Management, 275, 117-129. https://doi.org/10.1016/j. foreco.2012.03.003

Osborne, P.E. and Suárez-Seoane, S. (2002) Should data be partitioned spatially before building large-scale distribution models? Ecological Modelling, 157, 249-259. https://doi.org/10.1016/ S0304-3800(02)00198-9

Osborne, P.E., Foody, G.M. and Suárez-Seoane, S. (2007) Nonstationarity and local approaches to modelling the distributions of wildlife. Diversity and Distributions, 13, 313-323. https://doi. org/10.1111/j.1472-4642.2007.00344.x

Oshiro, T.M., Perez, P.S. and Baranauskas, J.A. (2012) How many trees in a random forest? In: Perner, P. (Ed.) Machine Learning and Data Mining in Pattern Recognition. Berlin: Springer-Verlag, pp. 154-168.

Pausas, J.G. (2001) Resprouting vs seeding - a Mediterranean perspective. Oikos, 94, 193-194. https://doi.org/10.1034/j.1600-0706.2001. t01-1-10979.x

Pausas, J.G. and Keeley, J.E. (2014) Evolutionary ecology of resprouting and seeding in fire-prone ecosystems. New Phytologist, 204, 55-65. https://doi.org/10.1111/nph.12921

Pausas, J.G. and Lloret, F. (2007) Spatial and temporal patterns of plant functional types under simulated fire regimes. International Journal of Wildland Fire, 16, 484-492. https://doi.org/10.1071/WF06109

Pausas, J.G. and Vallejo, V.R. (1999) The role of fire in European Mediterranean ecosystems. In: Chuvieco, E. (Ed.) Remote sensing of large wildfires in the European Mediterranean basin. Berlin: SpringerVerlag, pp. 3-6.
Pausas, J.G., Bradstock, R.A., Keith, D.A. and Keeley, J.E. (2004) Plant functional traits in relation to fire in crown-fire ecosystems. Ecology, 85, 1085-1100. https://doi.org/10.1890/02-4094

Pausas, J.G., Llovet, J., Rodrigo, A. and Vallejo, R. (2008) Are wildfires a disaster in the Mediterranean basin? A review. International Journal of Wildland Fire, 17, 713-723. https://doi.org/10.1071/WF07151

Poursanidis, D. and Chrysoulakis, N. (2017). Remote Sensing, natural hazards and the contribution of ESA Sentinels missions. Remote Sensing Applications: Society and Environment, 6, 25-38. https://doi. org/10.1016/j.rsase.2017.02.001.

Probst, P. and Boulesteix, A.L. (2018) To tune or not to tune the number of trees in Random Forest. Journal of Machine Learning Research, 18, 1-18.

$\mathrm{Pu}, \mathrm{R}$. and Cheng, J. (2015) Mapping forest leaf area index using reflectance and textural information derived from WorldView-2 imagery in a mixed natural forest area in Florida, US. International Journal of Applied Earth Observation and Geoinformation, 42, 11-23. https://doi. org/10.1016/j.jag.2015.05.004

Quintano, C., Fernández-Manso, A., Calvo, L., Marcos, E. and Valbuena, L. (2015) Land Surface temperature as potential indicator of burn severity in forest Mediterranean ecosystems. International Journal of Applied Earth Observation and Geoinformation, 36, 1-12. https://doi. org/10.1016/j.jag.2014.10.015

R Core Team. (2017) R: A language and environment for statistical computing. Vienna, Austria: R Foundation for Statistical Computing Retrieved from https://www.R-project.org/

Regos, A., Gagne, L., Alcaraz-Segura, D., Honrado, J.P. and Domínguez, J. (2019) Effects of species traits and environmental predictors on performance and transferability of ecological niche models. Scientific Reports, 9, 4221. https://doi.org/10.1038/s41598-019-40766-5

Sarker, L.R. and Nichol, J.E. (2011) Improved forest biomass estimates using ALOS AVNIR-2 texture indices. Remote Sensing of Environment, 115, 968-977. https://doi.org/10.1016/j.rse.2010.11.010

Schile, L.M., Byrd, K.B., Windham-Myers, L. and Kelly, M. (2013) Accounting for non-photosynthetic vegetation in remote-sensing-based estimates of carbon flux in wetlands. Remote Sensing Letters, 4, 542-551. https://doi.org/10.1080/2150704X.2013.766372

Schoennagel, T., Smithwick, A.H. and Turner, M.G. (2008) Landscape heterogeneity following large fires: insights from Yellowstone National Park, USA. International Journal of Wildland Fire, 17, 742-753. https:// doi.org/10.1071/WF07146

Schumacher, P., Mislimshoeva, B., Brenning, A., Zandler, H., Brandt, M., Samimi, C. and et al (2016) Do Red edge and texture attributes from high-resolution satellite data improve wood volume estimation in a semi-arid mountainous region? Remote Sensing, 8, 540. https://doi. org/10.3390/rs8070540

Sequeira, A.M.M., Bouchet, P.J., Yates, K.L., Mengersen, K. and Caley, M.J. (2018) Transferring biodiversity models for conservation: Opportunities and challenges. Methods in Ecology and Evolution, 9, 1250-1264. https://doi.org/10.1111/2041-210X.12998

Stefanov, W.L. and Netzband, M. (2005) Assessment of ASTER land cover and MODIS NDVI data at multiple scales for ecological characterization of an arid urban center. Remote Sensing of Environment, 99, 31-43. https://doi.org/10.1016/j.rse.2005.04.024

Stephens, S.L., Burrows, N., Buyantuyev, A., Gray, R.W., Keane, R.E., Kubian, R. et al (2014) Temperate and boreal forest mega-fires: characteristics and challenges. Frontiers in Ecology and the Environment, 12, 115-122. https://doi.org/10.1890/120332

Street, G.M., Van der Vennen, L.M., Avgar, T., Mosser, A., Anderson, M.L., Rodgers, A.R. and et al (2015) Habitat selection following recent disturbance: model transferability with implications for management and conservation of moose (Alces alces). Canadian Journal of Zoology, 93, 813-821. https://doi.org/10.1139/cjz-2015-0005

Suárez-Seoane, S., Virgós, E., Terroba, O., Pardavila, X. and Barea-Azcón, J.M. (2014) Scaling of species distribution models across spatial 
resolutions and extents along a biogeographic gradient. The case of the Iberian mole Talpa occidentalis. Ecography, 37, 279-292. https:// doi.org/10.1111/j.1600-0587.2013.00077.x

Syphard, A.D. and Franklin, J. (2010) Species traits affect the performance of species distribution models for plants in southern California. Journal of Vegetation Science, 21, 177-189. https://doi. org/10.1111/j.1654-1103.2009.01133.x

Taboada, A., Tárrega, R., Marcos, E., Valbuena, L., Suárez-Seoane, S. and Calvo, L. (2017) Fire recurrence and emergency post-fire management influence seedling recruitment and growth by altering plant interactions in fire-prone ecosystems. Forest Ecology and Management, 402, 63-75. https://doi.org/10.1016/j.foreco.2017.07.029

Taboada, A., Fernández-García, V., Marcos, E. and Calvo, L. (2018) Interactions between large high-severity fires and salvage logging on a short return interval reduce the regrowth of fire-prone serotinous forests. Forest Ecology and Management, 414, 54-63. https:// doi.org/10.1016/j.foreco.2018.02.013

Thenkabail, P.S., Lyon, J.G. and Huete, A. (Eds.) (2011) Hyperspectral Remote Sensing of Vegetation. Boca Ratón: CRC Press.

Thomas, F.M. and Vesk, P.A. (2017) Are trait-growth models transferable? Predicting multi-species growth trajectories between ecosystems using plant functional traits. PLoS One, 12(5), e0176959. https:// doi.org/10.1371/journal.pone.0176959

Thuiller, W., Brotons, L., Araújo, M.B. and Lavorel, S. (2004) Effects of restricting environmental range of data to project current and future species distributions. Ecography, 27, 165-172. https://doi. org/10.1111/j.0906-7590.2004.03673.x

Tsalyuk, M., Kelly, M. and Getz, W.M. (2017) Improving the prediction of African savanna vegetation variables using time series of MODIS products. ISPRS Journal of Photogrammetry and Remote Sensing, 131. 77-91. https://doi.org/10.1016/j.isprsjprs.2017.07.012

Ustin, S.L. and Gamon, J.A. (2010) Remote sensing of plant functional types. New Phytologist, 186, 795-816. https://doi. org/10.1111/j.1469-8137.2010.03284.x

Verrelst, J., Geerling, G.W., Sykora, K.V. and Clevers, J.G.P.W. (2009) Mapping of aggregated floodplain plant communities using image fusion of CASI and LiDAR data. International Journal of Applied Earth Observation and Geoinformation, 11, 83-94. https://doi. org/10.1016/j.jag.2008.09.001

Viedma, O., Torres, I., Pérez, B. and Moreno, J.M. (2012) Modeling plant species richness using reflectance and texture data derived from QuickBird in a recently burned area of Central Spain. Remote Sensing of Environment, 119, 208-221. https://doi.org/10.1016/j. rse.2011.12.024

Wehlage, D.C., Gamon, J.A., Thayer, D. and Hildebrand, D.V. (2016) Interannual variability in dry mixed-grass Prairie Yield: A comparison of MODIS, SPOT, and Field measurements. Remote Sensing, 8, 872. https://doi.org/10.3390/rs8100872

Wenger, S.J. and Olden, J.D. (2012) Assessing transferability of ecological models: an underappreciated aspect of statistical validation. Methods in Ecology and Evolution, 3, 260-267. https://doi. org/10.1111/j.2041-210X.2011.00170.x

Wenger, S.J., Isaak, D.J., Dunham, J.B., Fausch, K.D., Luce, C.H., Neville, H.M. et al (2011) Role of climate and invasive species in structuring trout distributions in the Interior Columbia Basin. Canadian
Journal of Fisheries and Aquatic Sciences, 68, 988-1008. https://doi. org/10.1139/f2011-034

Werkowska, W., Márquez, A., Real, R. and Acevedo, P. (2017) A practical overview of transferability in species distribution modeling. Environmental Reviews, 25, 127-133. https://doi.org/10.1139/ er-2016-0045

Whittingham, M.J., Krebs, J.R., Swetnam, R.D., Vickery, J.A., Wilson, J.D. and Freckleton, R.P. (2007) Should conservation strategies consider spatial generality? Farmland birds show regional not national patterns of habitat association. Ecological Letters, 10, 25-35. https://doi. org/10.1111/j.1461-0248.2006.00992.x

Wood, E.M., Pidgeon, A.M., Radeloff, V.C. and Keuler, N.S. (2012) Image texture as a remotely sensed measure of vegetation structure. Remote Sensing of the Environment, 121, 516-526. https://doi. org/10.1016/j.rse.2012.01.003

Xiao, J. and Moody, A. (2005) A comparison of methods for estimating fractional green vegetation cover within a desert-to-upland transition zone in central New Mexico, USA. Remote Sensing of Environment, 98, 237-250. https://doi.org/10.1016/j.rse.2005.07.011

Xie, Q., Dash, J., Huang, W., Peng, D., Qin, Q., Mortimer, H. et al (2018) Vegetation indices combining the red and red-edge spectral information for Leaf Area Index retrieval. IEEE Journal of Selected Topics in Applied Earth Observations and Remote Sensing, 11, 1482-1493. https://doi.org/10.1109/JSTARS.2018.2813281

Yates, K.L., Bouchet, P.J., Caley, M.J., Mengersen, K., Randin, C.F., Parnell, S. et al (2018) Outstanding challenges in the transferability of ecological models. Trends in Ecology \& Evolution, 33, 790-802. https://doi.org/10.1016/j.tree.2018.08.001

Zhang, C. and Xie, Z. (2012) Combining object-based texture measures with a neural network for vegetation mapping in the Everglades from hyperspectral imagery. Remote Sensing of the Environment, 124, 310320. https://doi.org/10.1016/j.rse.2012.05.015

\section{SUPPORTING INFORMATION}

Additional supporting information may be found online in the Supporting Information section.

Appendix S1. Species list of each study site

Appendix S2. Vegetation spectral reflectance in the electromagnetic spectrum

Appendix S3. Second-order texture measures calculation using the Gray Level Co-Occurrence Matrix (GLCM)

How to cite this article: Fernández-Guisuraga JM, SuárezSeoane S, Calvo L. Transferability of vegetation recovery models based on remote sensing across different fire regimes. Appl Veg Sci. 2020;00:1-11. https://doi.org/10.1111/ avsc. 12500 


\section{Graphical Abstract}

The contents of this page will be used as part of the graphical abstract of html only. It will not be published as part of main article.

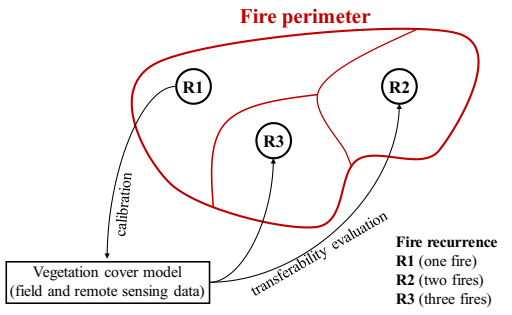

We evaluate transferability between fire recurrence scenarios of post-fire vegetation cover models calibrated with satellite imagery data. The best transferability results were obtained between areas with more homogeneous community composition arising from the species regenerative traits. The use of fine-grained satellite imagery for model calibration exhibited the lowest transferability error. 